\title{
Incidence and characteristics of voluntary nystagmus
}

\author{
J O S E P H R Z Z A N \\ From the Bascom-Palmer Eye Institute, University of Miami, Department of Ophthalmology, \\ Miami, Florida, USA
}

SUMMARY A survey of a college age population revealed that $8 \%$ could produce voluntary nystagmus. Seventy-nine per cent of this sample had relatives who could also produce it. A systematic investigation of the characteristics of voluntary nystagmus under a number of stimulus conditions showed that it resembles pendular nystagmus in waveform, and certain ocular oscillations, such as ocular flutter and opsoclonus, in frequency. The results indicate that voluntary nystagmus can be differentiated from other forms of nystagmus by its frequency, duration, and occurrence in individuals whose neuro-ophthalmological examination is normal. Voluntary nystagmus probably involves the "hold" mechanism of the cerebellar nuclei because of its frequency correspondence to ocular oscillations which result from a dysfunction in this anatomical area.

Early in the 19th century several clinicians reported that certain individuals could initiate nystagmus-like eye movements (Duke Elder, 1949). This voluntary nystagmus-also known as voluntary ocular tremor, voluntary ocular fibrillation, and voluntary ocular oscillation-has been defined as a high frequency, low amplitude movement of the eyes initiated and terminated on command (Friedman and Blodgett, 1955; Wist and Collins, 1964; Blair et al., 1967; Coren and Komada, 1972; Aschoff et al., 1976).

Most neuro-ophthalmology texts give perfunctory accounts of voluntary nystagmus, considering it a "trick" exhibited to amuse friends (Walsh and Hoyt, 1969). As a trick voluntary nystagmus may cause some confusion during routine neuroophthalmological examination. To circumvent this problem the studies to follow estimate the incidence of voluntary nystagmus and provide an analysis of its differentiating characteristics. The mechanism is discussed in relation to these data.

\section{Incidence of voluntary nystagmus}

Voluntary nystagmus has been described in the literature for over 100 years and there are, to date, about 600 reported cases. Duke Elder (1949) provided 32 references dating from 1866 . Wist and

\footnotetext{
Address for reprint requests: Dr J. R. Zahn, Bascom-Palmer Eye Institute, PO Box 520875, Biscayne Annex, Miami, Florida 33152, USA.

Accepted 22 December 1977
}

Collins (1964) compiled 39 references from different countries, and Sobrinho (1950) identified 300 cases in the South-American literature. Although the incidence of voluntary nystagmus has been suggested to be high (Duke Elder, 1949), it has not been determined.

To estimate the incidence, a questionnaire was administered to a large sample of students at Indiana University. The students were read the following statement: "The purpose of this questionnaire is to determine the incidence of individuals who have the unique ability to 'jiggle their eyes.' This is known as voluntary nystagmus. Certain signs usually are involved, but not necessarily, when voluntary nystagmus is produced, such as an apparent movement and blur of objects, strong converging or crossing of the eyes, and a feeling of muscle pull." The subjects were asked: "Are you able to produce voluntary nystagmus?" and "Does anyone in your family do this?"

Six hundred and thirty-four students, representing $2 \%$ of each academic class (freshman through graduate), were given the questionnaire. Fifty males and 28 females $(12.3 \%)$ reported that they could "jiggle their eyes." These individuals were tested, using an infrared eye monitoring system to document the validity of their report.

Fifty-two subjects from this sample could initiate voluntary nystagmus, while four slightly oscillated their eyes, and 13 could not produce voluntary nystagmus or had another type of nystagmus-for example, congenital pendular 
nystagmus. Nine subjects could not be contacted for testing. Thus, this survey showed that $8 \%(52$ out of 634) of this population could initiate voluntary nystagmus.

How and when an individual recognises this ability is unknown. One testimony is representative. A woman reported that she noticed, as a child, that if she moved her eyes quickly she could occasionally see "streaks of light." By placing "tension on her eyes" and defocusing she learned to elicit the desired sensory effect for brief periods.

Questioning of our subjects revealed that 39 $(75 \%)$ first initiated voluntary nystagmus between 7 and 8 years of age, while the remaining subjects did so between 10 and 20 years. The younger age group usually learned to produce it without training, while the older group learned the response after observing a relative or friend.

Forty-one (79\%) subjects reported that someone in their family could produce voluntary nystagmus. Twenty-six $(62 \%)$ subjects were in the same generation-namely, 11 brothers $(41 \%)$ nine sisters $(38 \%)$, and six cousins $(21 \%) ; 15(37 \%)$ subjects were in a previous generation-namely, seven fathers $(43 \%)$, five mothers $(35 \%)$, and three uncles $(22 \%)$. These data suggest, indirectly, a genetic element in support of previous investigators (Keyes, 1973; Aschoff et al., 1976) but do not necessarily rule out the contention that voluntary nystagmus is a learned ability (Luhr and Eckel, 1933; Coren and Komada, 1972).

\section{Characteristics of voluntary nystagmus}

Most reports on voluntary nystagmus have been based on conjecture or clinical observation. Only recent investigations have manipulated systematically crucial variables (Wist and Collins, 1964; Blair et al., 1967; Coren and Komada, 1972) and used electro-oculography (Westheimer, 1954; Goldberg and Jampel, 1962; Wist and Collins, 1964; Blair et al., 1967; Keyes, 1973; Aschoff et al., 1976; Jarrett et al., 1977), cinematography (Friedman and Blodgett, 1955), or a photoelectric technique (Coren and Komada, 1972) to monitor the phenomenon.

Westheimer (1954) reported a nystagmus frequency of $10 \mathrm{~Hz}$ with an amplitude of $5^{\circ}$, while Goldberg and Jampel (1962) showed, for two subjects, frequencies of 23 and $19 \mathrm{~Hz}$ and amplitudes of $5^{\circ}$ and $10^{\circ}$, respectively.

Wist and Collins (1964) reported a frequency of 12 to $13 \mathrm{~Hz}$ and an amplitude range of $1.2^{\circ}$ to $5.9^{\circ}$ for one subject. The frequency did not change for testing with and without a fixation target and in total darkness. The frequency when the eyes were closed was less than in total darkness, and a slight decline in frequency was found for positions $20^{\circ}$ left and right of a straight ahead position, but not for $20^{\circ}$ up and down. Convergence was not necessary for the initiation of voluntary nystagmus

Blair et al. (1967) found a frequency range of 16 to $18 \mathrm{~Hz}$, an average amplitude of $5^{\circ}$, and durations for three subjects of $2.5,4$, and $9 \mathrm{~s}$, respectively. There was no effect on the frequency and amplitude of voluntary nystagmus when spherical lenses $( \pm 3$ diopters) and prisms were placed in front of the eyes, nor during occlusion of either eye, eyes closed or eye position $\left(25^{\circ}\right.$ right, left; $15^{\circ}$ up, down) conditions. Cycloplegia had no effect. Unilateral voluntary nystagmus was demonstrated during conditions of occlusion, eyes closed, and gaze position in one subject. Convergence was not necessary to initiate it, and there was no voluntary control over the rate or the amplitude.

Coren and Komada (1972) found modal frequencies of 20 and $12 \mathrm{~Hz}$, and median amplitudes of $6^{\circ}$ and $1^{\circ}$ for the horizontal and vertical eye movements of one subject. The duration ranged from 25 to $35 \mathrm{~s}$. An empty field, occlusion, and viewing horizontal and vertical lines of light did not alter the voluntary nystagmus. The subject showed no control over the frequency, and limited control of the amplitude.

Aschoff et al. (1976) found for two subjects a frequency of $18 \mathrm{~Hz}$, an amplitude of $4^{\circ}$, and durations of 8 and $15 \mathrm{~s}$. Voluntary nystagmus could be elicited at $20^{\circ}$ gaze angle, in the dark, and with the eyes closed.

Jarrett et al. (1977) showed, for five subjects, a range of frequencies from 9 to $28 \mathrm{~Hz}$, and, amplitudes from $1^{\circ}$ to $9^{\circ}$. A spherical lens $(+6.00$

Table Characteristics of voluntary nystagmus summarised from previous literature

\begin{tabular}{llll}
\hline & \multicolumn{2}{l}{ Voluntary nystagmus } & \\
\cline { 2 - 4 } & Minimum & Maximum & Mean \\
\hline Frequency (Hz) & 5 & 28 & 16 \\
Amplitude ( $\left.{ }^{\circ}\right)$ & 1.0 & 20 & 5.2 \\
Duration (s) & 4 & 50 & 22.4 \\
Subjects & 13 male, 7 female & \\
Age range (yr) & 8 to 48 & \\
Age of initiation (yr) & 6 to 9 & Conjugate, pendular; horizontal/vertical \\
Occurring conditions & binocular/monocular; with/without \\
& convergence; all eye positions within \\
& 20 degrees; during darkness, occlusion, \\
& eyes open or closed & \\
Pathology & Healthy, normal with unremarkable \\
& neurological history; some may have \\
Aetiology & slight colour and/or muscle weakness \\
\hline
\end{tabular}


diopters) decreased it. Initiation of voluntary nystagmus was dependent upon convergence for three subjects and whether the eyes were open or closed.

The Table summarises the results of previous studies regardless of testing conditions.

These experiments neither manipulated the independent variables systematically nor used an adequate number of subjects. The present experiment was designed, therefore, to overcome these limitations, and to determine the extent of visual sensory and ocular motor system involvement in the initiation and maintenance of voluntary nystagmus. The subjects were drawn from those individuals identified by the questionnaire.

\section{Subjects and method}

Ten subjects, five men and five women, ranging in age from 18 to 24 years participated in this experiment. Optometric examination revealed corrected Snellen acuities to $20 / 20$ in each eye for five subjects. The refractive error for four corrected subjects was within minus two diopters. The alternate cover test showed heterophoria for six subjects, esophoria or exophoria within four prism diopters for four subjects at 40 centimetres, and heterophoria at six metres for these subjects. Version and vergence amplitudes, near point of convergence, and the pupil response were normal for all subjects. Four male subjects had slight redgreen deficiency (Farnsworth-Munsell 100 Hue Test). Ophthalmoscopic examination showed clear media and fundi in all subjects. The history of each subject was unremarkable, showing no trauma, ocular surgery, inflammation, or mental disease. The subjects had not taken any drugs and were under no medication at the time of testing.

\section{EYE MOVEMENT MONITOR}

Voluntary nystagmus was monitored by an infrared eye monitoring system (Space Sciences Model $\mathrm{SGH} / \mathrm{V}-2$ ). This system has a $100 \mathrm{~Hz}$ bandpass and a linear angular range horizontally to $20^{\circ}$. Voluntary nystagmus was recorded on a Grass polygraph model 7PCPA $(25 \mathrm{~mm} / \mathrm{s})$ and separately stored on FM tape (Hewlett-Packard instrumentation tape recorder, model $3960 \mathrm{H}$, series 936). The data could be analysed to within an accuracy of $0.5^{\circ}$. Electro-oculography with a $30 \mathrm{~Hz}$ bandpass and an accuracy of $1^{\circ}$ was used for the eyes closed condition.

For each subject the frequency of the response was defined as the number of complete cycles occurring within a prescribed time period, usually $20 \mathrm{~s}$, and the amplitude was the average peak-to- peak measurement for five full cycles occurring in the middle of each response.

\section{EXPERIMENTAL TASKS}

\section{Luminance}

Each subject was asked to initiate voluntary nystagmus while fixing the centre of a $60^{\circ}$ white panel held at $1500 \mathrm{~mm}$ and varied in luminance $(5,50,500 \mathrm{ft}-\mathrm{L})$. Also included were eyes closed and darkness conditions.

\section{Stimulus distance}

Each subject was asked to initiate voluntary nystagmus while fixing one minute of arc Snellen letters located at various distances $(100,400,1000$, 1500,3000 , and $6000 \mathrm{~mm}$ ) in front of and perpendicular to the subject's pupillary distance.

\section{Radial position}

Each subject was asked to initiate voluntary nystagmus while fixing a red $1^{\circ}$ light-emitting diode located at $5^{\circ}, 10^{\circ}, 15^{\circ}$, and $20^{\circ}$ to the right and to the left of a $0^{\circ}$ position.

\section{Response control}

Each subject was tested on their ability to change the frequency of voluntary nystagmus while fixing a red $1^{\circ}$ light-emitting diode located six metres in front of the subject.

\section{Duration sequence}

During each experimental task, the subject was asked to maintain voluntary nystagmus for as long as possible for each of three successive trials.

\section{PROCEDURE}

The subject was seated comfortably in an adjustable chair in front of an ophthalmic instrument table contained within a shielded light-tight room painted flat black. The subject's head was held firmly by a chin cup and an adjustable head clamp.

During each experimental task, the subject, on command from the experimenter, initiated voluntary nystagmus. Before starting, a time mark was placed on the polygraph and on the tape recorder by the subject depressing a hand-held switch. One practice trial per task was permitted. If the subject did not respond after $5 \mathrm{~s}$, the task was terminated, and the instructions for the next task administered. Both monocular and binocular testing were done. Except for the duration sequence, the periods of testing were kept to a set duration of $2 \mathrm{~min}$, with a 1 min rest interval between tasks. The data were obtained in two one hour sessions for each subject. Ten trials were obtained from each subject on each experimental task. 


\section{Results}

\section{GENERAL CHARACTERISTICS}

The voluntary nystagmus of 10 subjects was pendular and conjugate. The ranges for the frequency, the amplitude, and the duration were between 4 and $24 \mathrm{~Hz}, 4^{\circ}$ and $11^{\circ}$, and $2 \mathrm{~s}$ and $90 \mathrm{~s}$ respectively, across all experimental conditions. The overall means (and standard deviations) of the frequency, amplitude, and duration for all conditions were $16.3(5.1) \mathrm{Hz}, 6.1^{\circ}\left(2.6^{\circ}\right)$, and 19.8 (6.6) $\mathrm{s}$ respectively. The results found here agree in waveform, frequency range, amplitude, initiation procedure, and duration with most previous reports. No significant difference was found between the men and women, so subsequent analyses are based on the combined data.

\section{LUMINANCE}

Figure 1 shows the average frequency and amplitude for each eye of 10 subjects across the luminance $(5,50,500 \mathrm{ft}-\mathrm{L})$, eyes closed, and darkness conditions. The bars around each data point represent the range. The means (and standard deviations) of the frequency and amplitude for these conditions (luminance being combined) were $16.8(5.6) \mathrm{Hz}, 17.8(5.9) \mathrm{Hz}, 18.2(3.1) \mathrm{Hz}$, and $6.7^{\circ}\left(2.2^{\circ}, 6.7^{\circ}\left(2.5^{\circ}\right), 6.8^{\circ}\left(2.4^{\circ}\right)\right.$ respectively.
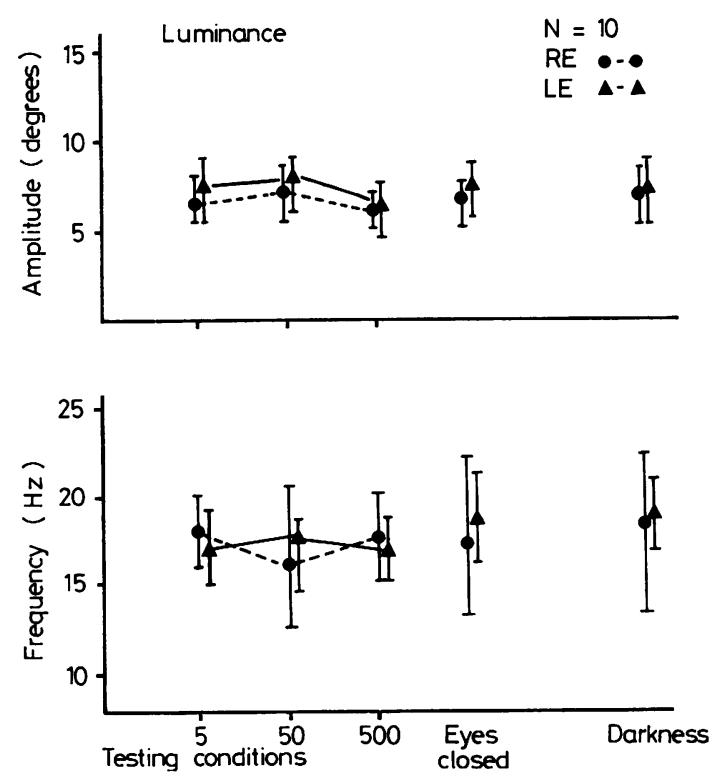

Fig. 1 Frequency and amplitude of voluntary nystagmus for each eye under three luminance levels $(5,50,500 \mathrm{ft}-\mathrm{L})$, with the eyes closed, and in darkness. Each data point represents mean for 10 subjects. Bars represent range.
These data are similar to the results of studies testing equivalent conditions (Wist and Collins, 1964; Blair et al., 1967; Ashoff 1976; Jarrett et al., 1977).

Figure 2 shows voluntary nystagmus for one subject across the occlusion, eyes closed, and darkness conditions. These data graphically demonstrate, contrary to some previous investigators (Goldberg and Jampel, 1962; Blair et al., 1967), no effect on voluntary nystagmus across these conditions.

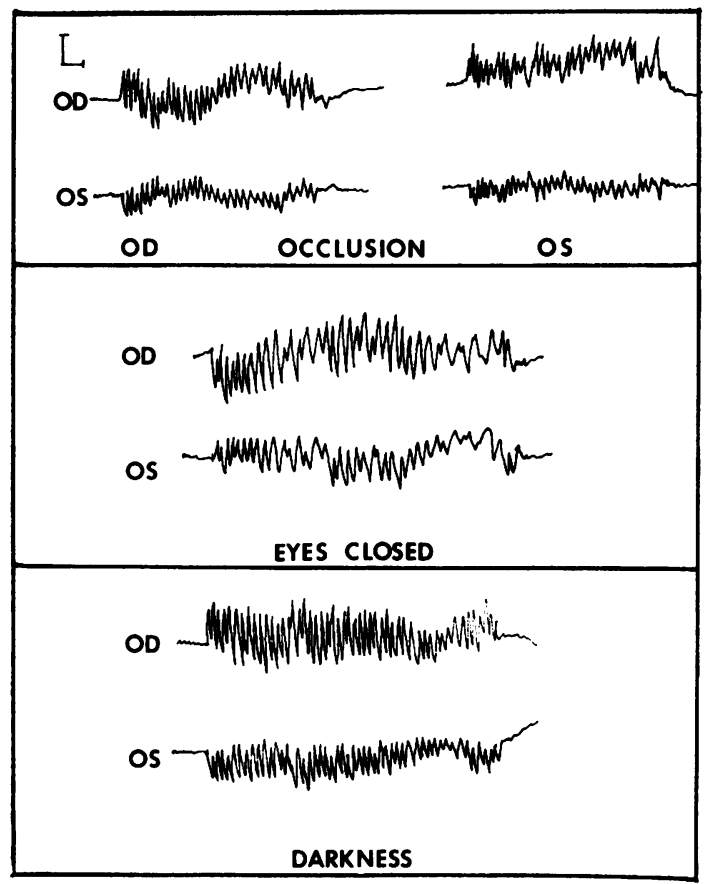

Fig. 2 Infrared eye movement recordings of voluntary nystagmus for each eye during darkness and occlusion conditions, and electro-oculographic recordings with the eyes closed. Upper and lower records are for right and left eyes respectively. Scale factors shown at upper left are $5^{\circ}$ (ordinate) and 200 ms (abscissa). Details of recording technique can be found in text.

EYE POSITION

The means of frequency and amplitude for all eye positions across subjects are shown in Fig. 3. The bars represent the range. These data indicate a significantly decreased $(P<0.01)$ frequency for the $15^{\circ}$ and $20^{\circ}$ eye positions on both sides of the $0^{\circ}$ position. No trend was found for the amplitude. The voluntary nystagmus for one subject is shown in Fig. 4. These data support some previous observations (Luhr and Eckel, 1933; Friedman and Blodgett, 1955; Wist and Collins, 1964; Blair et 

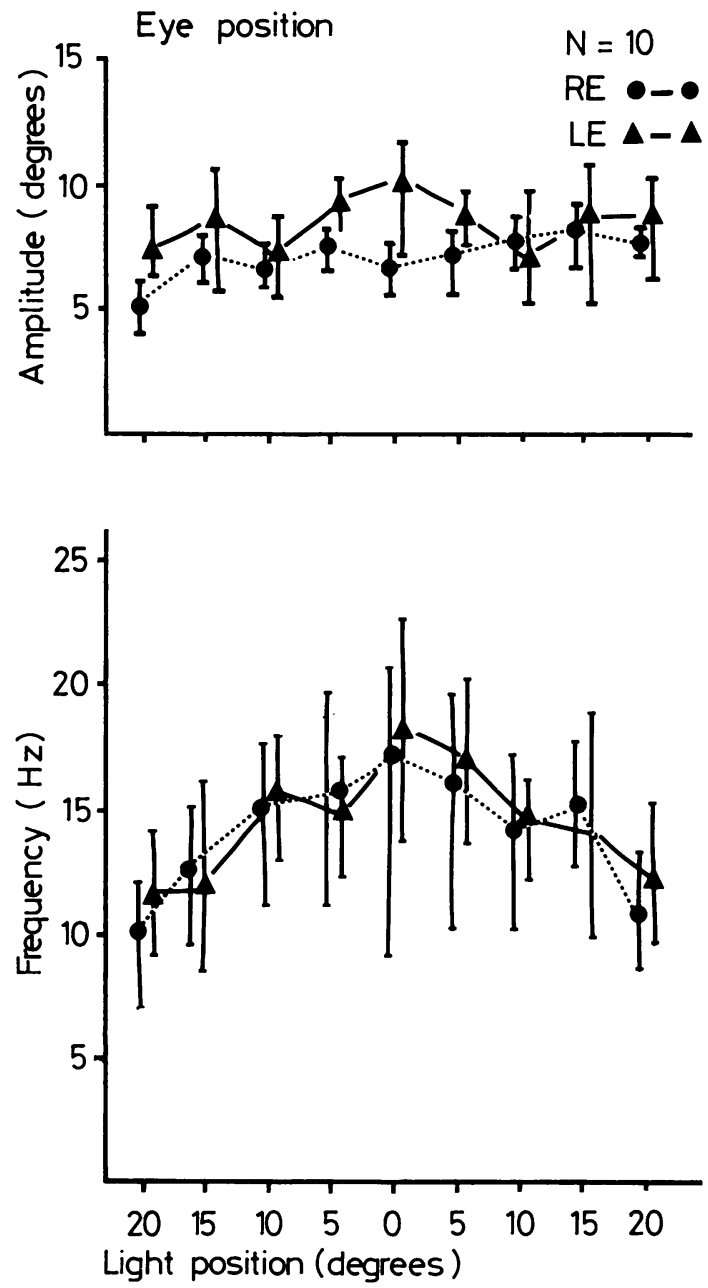

Fig. 3 Frequency and amplitude of voluntary nystagmus while fixing a $1^{\circ}$ red light-emitting diode located at various positions along the horizontal meridian. Each data point represents mean for 10 subjects. Bars represent range.

al., 1967; Keyes, 1973) but not those of Goldberg and Jampel (1962).

\section{STIMULUS DISTANCE}

The means of frequency and amplitude for all subjects for different stimulus distances are shown in Fig. 5. The bars represent the range. The combined means (and standard deviations) are 12.1 (4.0) $\mathrm{Hz}$ and $7.1^{\circ}\left(2.5^{\circ}\right)$ respectively. These data and the tracings shown in Figs. 2 and 4 indicate, in agreement with others (Friedman and Blodgett, 1933; Westheimer, 1954; Goldberg and Jampel, 1962; Wist and Collins, 1964; Jarrett et al., 1977,

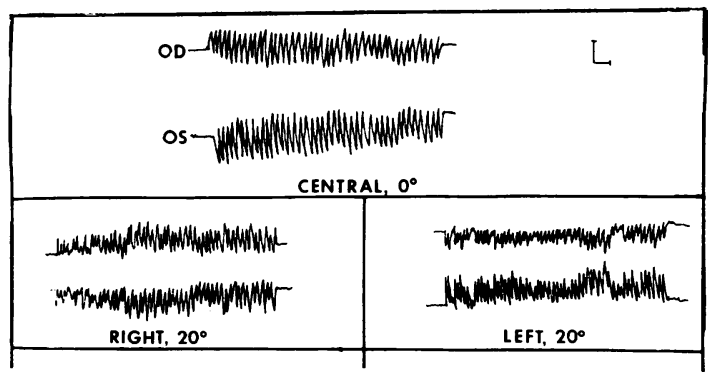

Fig. 4 Voluntary nystagmus for each eye while fixing under normal room illumination a $1^{\circ}$ light-emitting diode located at the $0^{\circ}$ and $20^{\circ}$ left and right positions along the horizontal meridian. Upper and lower records of each set are for the right and left eyes respectively. Scale factors shown at upper right are $5^{\circ}$ (ordinate) and $200 \mathrm{~ms}$ (abscissa).
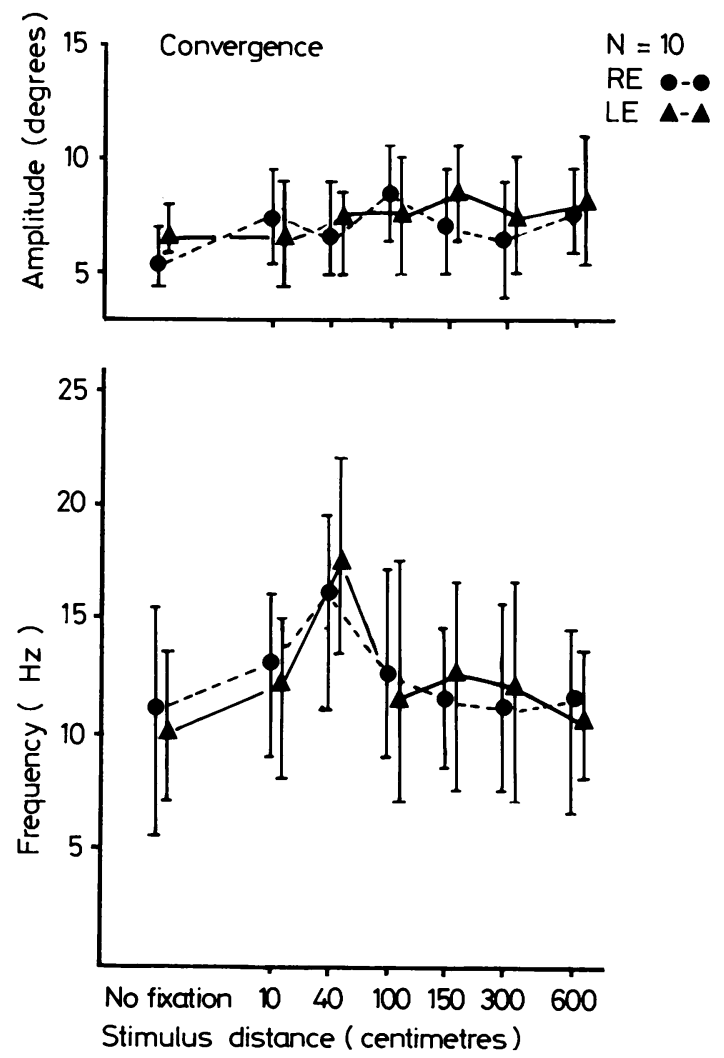

Fig. 5 Frequency and amplitude of voluntary nystagmus for both eyes under normal room illumination while fixing on 1 minute arc Snellen letters located at various distances from the straight ahead position. Each data point represents mean for 10 subjects. Bars represent range. 
that stimulus distance (that is, convergence) may be associated with the initiation and, possibly, facilitation of voluntary nystagmus. Any confusion regarding the influence of convergence on voluntary nystagmus may be due simply to the fixation distance employed during testing.

RESPONSE CONTROL

One subject could vary the frequency of voluntary nystagmus. This can be seen in Fig. 6 (top). Average frequencies of $5.6 \mathrm{~Hz}, 10.7 \mathrm{~Hz}$, and $18.4 \mathrm{~Hz}$ and amplitudes of $7^{\circ}, 4.5^{\circ}$, and $1.5^{\circ}$ were recorded. Unlike the subject of Coren and Komada (1972), the present subject maintained a continuous response, rather than "short bursts of activity, followed by resting periods." Furthermore, this control is contrary to Blair et al. (1967) and Aschoff et al. (1976) who report control over the duration but not the rate or amplitude of voluntary nystagmus.

\section{DURATION SEQUENCE}

The frequency and amplitude of voluntary nystagmus could be maintained on the average for $25 \mathrm{~s}$ under all conditions. Figure 6 (bottom) shows relatively constant frequency and amplitude components when the first and last $15 \mathrm{~s}$ were compared for one subject who could produce voluntary nystagmus for $90 \mathrm{~s}$. After five to six trials separated by 10 to $30 \mathrm{~s}$, the duration decreased and an extended rest period was required, suggesting that the duration varies inversely with the number of trials.

\section{Discussion}

Our survey showed that $8 \%$ of a college age population could produce voluntary nystagmus. The ability is usually recognised at about 8 years of age. Seventy-nine per cent of this population claimed to have a relative who could produce voluntary nystagmus.

Voluntary nystagmus is a type of pendular nystagmus. Its frequency is greater than that found for latent, miner's, and gaze-paretic nystagmus $(4-5 \mathrm{~Hz})$, less than the tremor component of physiological nystagmus $(30-90 \mathrm{~Hz})$, but similar to certain types of ocular oscillations such as ocular flutter and opsoclonus $(13 \mathrm{~Hz})$, and to the convergence tremor of Elsching $(16-17 \mathrm{~Hz})$, except that the latter requires converged eyes (Higgins and Stultz, 1953; Gay et al., 1974; Ellenberger et al., 1976). As noted here, convergence may increase the frequency of voluntary nystagmus at $400 \mathrm{~mm}$

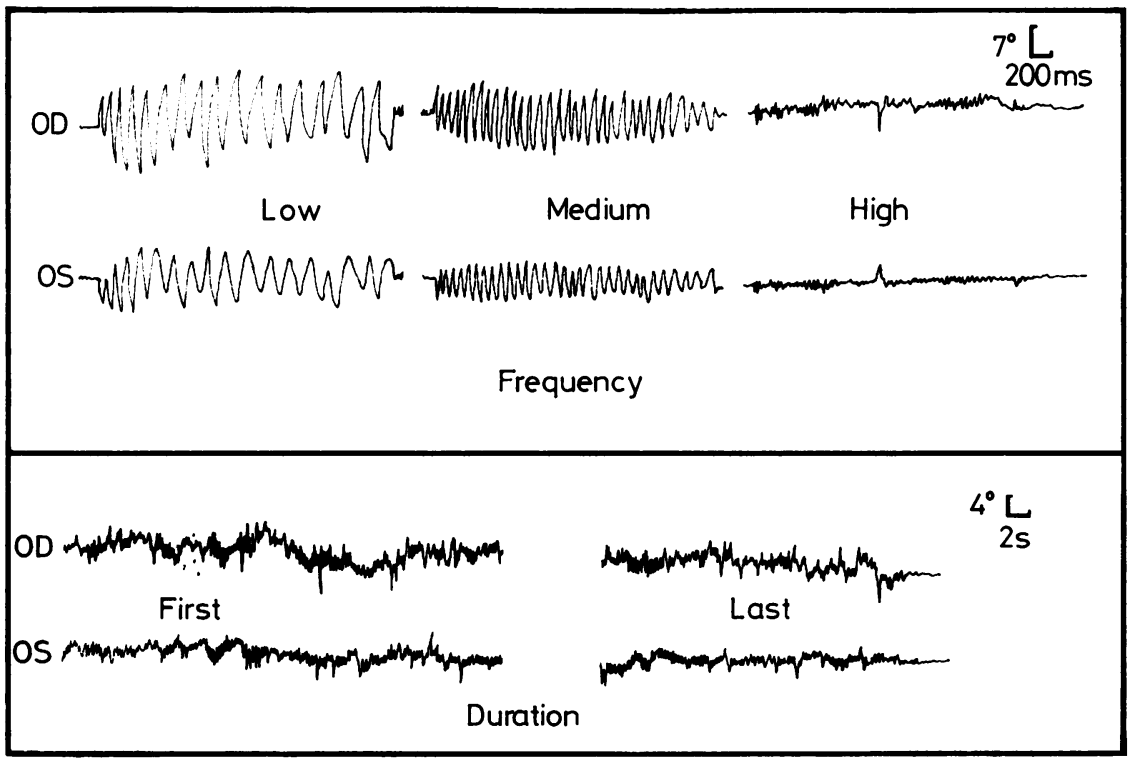

Fig. 6 Upper records show infrared eye movement recordings for one subject while attempting to change the frequency of voluntary nystagmus. The terms low $(6 \mathrm{~Hz})$, medium $(11 \mathrm{~Hz})$, and high $(18 \mathrm{~Hz})$ refer to the frequency ranges. There was a two minute rest period between the three frequency measures. Lower records show frequency and amplitude of voluntary nystagmus for the first and last 15 seconds of a 90 second record. 
but it is not necessary to maintain voluntary nystagmus. Furthermore, unlike congenital pendular nystagmus (Dell'Osso and Daroff, 1975), voluntary nystagmus does not require fixation for initiation and is not abolished with eye closure or darkness.

Taken together, these data indicate that voluntary nystagmus resembles, in waveform, pendular nystagmus and in frequency certain forms of ocular oscillations.

Voluntary nystagmus cannot be maintained, on the average, for more than $25 \mathrm{~s}$. Thus the duration and frequency of voluntary nystagmus permit differentiation from other forms of nystagmus. Furthermore, its similarity to oscillations which have been identified with dysfunctions of the cerebellar nuclei (Aschoff, 1974), in particular the "hold" mechanism (Kornhuber, 1974), suggest that voluntary nystagmus may be produced by this mechanism.

\section{References}

Aschoff, J. C. (1974). Reconsideration of the oculomotor pathway. In The Neurosciences: Third Study Group. Edited by F. O. Schmitt and F. G. Worden. Rockefeller University Press: New York.

Aschoff, J. C., Becker, W., and Rettelbach, R. (1976). Voluntary nystagmus in five generations. Journal of Neurology, Neurosurgery, and Psychiatry, 39, 300304.

Blair, C. J., Goldberg, M. F., and von Noorden, G. K. (1967). Voluntary nystagmus. Archives of Ophthalmology, 77, 349-354.

Coren, S. T., and Komada, M. K. (1972). Eye movement control in voluntary nystagmus. American Journal of Ophthalmology, 74, 1161-1165.

Dell'Osso, L. F., and Daroff, R. B. (1975). Congenital nystagmus waveforms and foveation strategy. Documenta Ophthalmologica, 39, 155-181.
Duke Elder, S. (1949). Textbook of Ophthalmology. Vol. 4, pp. 4238-4239. Henry Kimpton: London.

Ellenberger, C., Keltner, J. L., and Stroud, M. H. (1976). Ocular dyskinesia in cerebellar disease: evidence for the similarity of opsoclonus, ocular dysmetria, and flutter-like oscillations. Brain, 95, 685692.

Friedman, M. W., and Blodgett, R. M. (1955). Voluntary ocular fibrillation. American Journal of Ophthalmology, 39, 78-80.

Gay, A. J., Newman, N. W., Keltner, J. L., and Stroud, M. H. (1974). Eye Movement Disorders. C. V. Mosby: St Louis.

Goldberg, R. T., and Jampel, R. S. (1962). Voluntary nystagmus in a family. Archives of Ophthalmology, 68, 32-35.

Higgins, G. C., and Stultz, K. F. (1953). Frequency and amplitude of ocular tremor. Journal of the Optical Society of America, 43, 1136.

Jarrett, A., Emery, J. M., Coats, A. C., and Justice, J. (1977). Voluntary nystagmus. Annals of Ophthalmology, 9, 853-859.

Keyes, M. (1973). Voluntary nystagmus in two generations. Archives of Neurology (Chicago), 29, 63-64.

Kornhuber, H. H. (1974). Cerebral cortex, cerebellum, and basal ganglia: an introduction to their motor functions. In The Neurosciences: Third Study Group. Edited by F. O. Schmitt and F. G. Worden. Rockefeller University Press: New York.

Luhr, A. F., and Eckel, J. L. (1933). Fixation and voluntary nystagmus: clinical study. Archives of Ophthalmology, 9, 625-634.

Sobrinho, J. P. G. (1950). Consideracoes a respeito de um caso de nistagmus voluntario. Arqivos Brasileiros de Oftalmologia, 12, 126-127.

Walsh, F. B., and Hoyt, W. F. (1969). Clinical NeuroOphthalmology. Third edition. Williams and Wilkins: Baltimore.

Westheimer, G. (1954). A case of voluntary nystagmus. Ophthalmologica, 128, 300-303.

Wist, E. R., and Collins, W. E. (1964). Some characteristics of voluntary nystagmus. Archives of Ophthalmology, 72, 470-475. 